\title{
Health Facility-based Counselling and Community Outreach are Associated with Maternal Dietary Practices in a Cross-sectional Study from Tanzania
}

Kirk A. Dearden ( $\boldsymbol{\nabla}$ kdearden@corusinternational.org )

IMA World Health

Ramu Bishwakarma

Lutheran World Relief

Benjamin T. Crookston

Brigham Young University

Benesta T. Masau

IMA World Health

Generose I. Mulokozi

IMA World Health

\section{Research Article}

Keywords: Maternal, Dietary Practices, Tanzania, Counselling, Interpersonal Communication, Community Health Worker, Support Groups

Posted Date: February 5th, 2021

DOI: https://doi.org/10.21203/rs.3.rs-155318/v1

License: (c) (1) This work is licensed under a Creative Commons Attribution 4.0 International License.

Read Full License

Version of Record: A version of this preprint was published at BMC Nutrition on August 20th, 2021. See the published version at https://doi.org/10.1186/s40795-021-00447-x. 


\section{Abstract}

Background: Anemia and underweight among women are major public health challenges. Access to health services can improve dietary behaviors and women's nutritional status. We examined whether exposure to health services is associated with women's dietary practices in Tanzania.

Methods: Data come from a two-stage, randomized baseline survey among 5,000 female primary caregivers prior to implementing a maternal and child nutrition program. We ran frequencies on women's exposure to existing health facility-based counselling, community health worker visits, and attendance at women's support groups. We examined associations between exposure to these interventions and maternal diets and adjusted for sociodemographic covariates using ordinary least squares regression and ordered logistic regression.

Results: A third of the sample (34.1 percent) had received any antenatal care (ANC) during their most recent pregnancy or had been advised by anyone about nutrition (37.0 percent). 68.0 percent had never had a community health worker (CHW) speak to them about their children's health and 9.4 percent had participated in a women's group. Only 8.0 percent of mothers ate more than usual during pregnancy and 7.1 percent ate more types of foods. After adjusting for mother's age, education and household assets, women who received nutrition advice were 1.3 times (95 percent $\mathrm{Cl}: 1.1,1.7)$ more likely than mothers who did not to eat more during pregnancy. Receiving ANC and advice on nutrition before, during, and after pregnancy and delivery were highly associated with the mother eating more types of foods. Hearing from a CHW about children's health but not support group attendance was often associated with various dietary practices. Almost all measures of access to health services were significantly associated with mothers' frequency of eating in the previous 24 hours. Receiving advice on nutrition during pregnancy and after giving birth and CHW contact were associated with mothers' dietary diversity in the previous 24 hours.

Conclusions: Several program exposure variables-especially being counselled about nutrition-were associated with improved dietary practices. Improving service delivery at scale may contribute to improved dietary behaviors in larger populations, given the associations we describe, along with findings from the existing literature.

\section{Background}

While the prevalence of anemia among nonpregnant women of reproductive age has decreased from 43 percent in 1995 to 38 percent in 2011, [1] only a few countries are on track to meet the World Health Assembly target of a 50 percent reduction by 2025 [2]. Globally, 39 percent of all women of reproductive age are anemic, as are 46 percent of pregnant women in developing countries [3] with about one in 10 (9.7 percent) being underweight [2]. Anemia and underweight have long-term consequences for women and children, including increased maternal and child morbidity and mortality and impaired mental development [4-6]. 
Despite improvements in maternal and child health over the past 20 years, malnutrition in Tanzania remains a major challenge with 53 percent of pregnant women experiencing anemia (hemoglobin concentration $<11 \mathrm{~g} / \mathrm{dl}$ ), 10 percent of women of reproductive age suffering from underweight (body mass index $<18.5 \mathrm{~kg} / \mathrm{m} 2$ ), and 28 percent overweight or obese (body mass index $>=25 \mathrm{~kg} / \mathrm{m} 2$ ) [7].

Inadequate dietary intake is a major source of malnutrition $[4,6]$, yet in Tanzania, according to one study, only 46 percent of women and 26 percent of children report minimum dietary diversity and a minimum acceptable diet, respectively [8]. A national survey indicates that only 9 percent of children receive a minimum acceptable diet [7]. Given the large numbers of Tanzanian women less than 15 years of age, malnutrition will likely persist if the nutritional behaviors and practices of women of reproductive age remain sub-optimal.

Evidence suggests that activities such as dietary supplementation, food fortification and the promotion of dietary diversity improve maternal and child health outcomes [9]. Some studies indicate that having access to antenatal care services can positively influence birth outcomes including pre-term birth, birthweight, neonatal health, and the mothers' nutritional status [10-12], though several of these studies lack methodological rigor. Additional evidence suggests that providing nutrition education and counselling before and during pregnancy can improve maternal nutrition and neo-natal and child health [13-15]. As such, there is consensus that health clinics, community health volunteers, and community groups play an important role in the behavior change needed to improve health $[14,16,17]$.

Even though the Tanzanian government provides free maternal and child health care services [18], access to services remains a problem [19]. Documenting women's access to facility-based services and community outreach and understanding whether access to services is associated with women's improved dietary practices are critical to designing and implementing effective policies and programs.

This research assesses whether women's access to health services (through the government and through other implementing partners such as non-governmental organizations) is associated with dietary practices in pregnancy and post-partum. Specifically, we test the hypothesis that mothers with access to Tanzania's existing health services are more likely than mothers without access to these services to eat more food, eat more frequently, and consume more diverse foods during pregnancy. We expect that these associations persist after adjusting for sociodemographic covariates.

\section{Methods}

This study used data from a cross-sectional baseline survey conducted in January and February of 2016, prior to implementing a large, integrated nutrition project (Addressing Stunting in Tanzania Early or ASTUTE). In 2015, IMA World Health and its consortium partners launched a five-year projected funded by UKAid. The project targeted women and children in five Northwestern regions of Tanzania, collectively representing a population of 10.2 million and more than 750,000 stunted children. These five regions were selected because they had a high prevalence of stunting and anemia and poor maternal and child feeding practices relative to the rest of the country. The baseline informed program design. 
This study's intent is to 1) document government and other implementing partner program coverage prior to the start of the ASTUTE project, and 2) assess associations between exposure to existing government programs and maternal health practices. After baseline, the ASTUTE project was implemented in five lake zone regions of Tanzania (Geita, Kagera, Kigoma, Mwanza, and Shinyanga) and its primary objective was to reduce stunting among children under 5 years of age with improvements in maternal diets, antenatal care seeking, hand hygiene, sanitation, and other behaviors as secondary objectives. Future research will examine associations between exposure to social and behavior change activities that were implemented as part of the ASTUTE project, antenatal care seeking, and maternal diet.

Study participants include 5000 female primary caregivers of children aged 0 to 23 months. We recruited respondents from five geographic regions, including Geita, Kagera, Kigoma, Mwanza, and Shinyanga. We used two-stage probability proportional to size sampling, first at the district level and then at the village level in rural areas and neighborhoods in urban areas, employing data from Tanzania's most recent (2012) census as the sampling frame. Once randomly selected villages or neighborhoods were identified, we selected 20 households from within each village/neighborhood using a spin-the-bottle approach to choose an axis that interviewers could follow to identify the first household for interview. In rural areas, interviewers were required to identify houses at least 200 meters apart. In urban areas, we selected every fifth house for interview (in buildings with more than one eligible household, only one household was interviewed).

We field-tested the survey instrument among mothers and fathers then revised and finalized it prior to administration by IPSOS Tanzania, which is part of a global data collection firm. We scripted the questionnaire onto a mobile data collection platform and uploaded it to Android mobile devices used for data collection.

We obtained informed consent from all study participants-written if the respondent was literate and by thumb print if not. The National Institute for Medical Research in Tanzania and relevant local government authorities authorized the research (NIMR/HQ/R.8a/Vol.IX/2344). Three research teams, trained by IPSOS Tanzania, administered the questionnaire. Interviewers conducted one-hour face-to-face interviews in Kiswahili. Interviews took place at the caretaker's place of residence. We made three attempts to contact mothers in their residence, after which replacement households were selected. There were a total of 150 refusals in the five regions (2.9\% of all individuals contacted). Upon completion of data collection, IPSOS Tanzania compiled survey results for cleaning and analysis.

Outcomes included whether the mother, at any time during her most recent pregnancy resulting in the birth of the youngest living child, ate more than usual and consumed more types of foods than usual. Additional outcomes included the number of times the mother ate in the previous 24 hours and her dietary diversity based on seven food groups (grains, legumes and nuts, dairy, flesh foods, eggs, vitamin A rich foods, and other fruits), also measured for the 24 hours prior to interview. Each of these behaviors was self-reported. Our measure of dietary diversity differs somewhat from the current 10-item Minimum Dietary Diversity for Women (MDD-W) index used by the Food and Agriculture Organization [20]. In 
particular, the MDD-W considers pulses (beans, peas and lentils) to be separate from nuts and seeds. The MDD-W also includes a category for other vegetables, in addition to dark, green leafy vegetables. However, when our baseline was carried out (2016), the Food and Agriculture Organization had not yet published new guidance about measuring maternal dietary diversity. Thus, our dietary diversity score is consistent with global standards as of early 2016.

Wherever possible, we used the same questions as those used in the 2015 Tanzania Demographic and Health Survey (TDHS)[7]. However, the TDHS does not ask about the amount and types of food consumed during pregnancy, exposure to counselling on maternal nutrition, contact with community health workers, nor participation in support groups. Each question not included in the TDHS was pretested then modified based on results from pre-testing.

Demographic data included information on the mother (ethnicity, religion, years of schooling, literacy, and age plus whether she personally owned a mobile phone), household (housing construction and assets ownership, whether the household owned a radio or TV, and the number of other children in the family), and community (travel time to the nearest market and health facility). The asset indicator was created by summing the number of assets respondents indicated they owned out of 13 possible assets, including bicycles, cars, carts, radio, and television, among others. The household construction index was created based on the construction materials used for the floor, roof, and walls of the dwelling ranging from three (if the walls, floor, and roof were made of rudimentary materials) to nine (if the walls, floor, and roof were made of finished materials).

Stata 14.2 (College Station, Texas, USA) was used for all statistical analyses. We calculated chi-squares and t-tests to gauge unadjusted associations between exposure to health programs and services and measures of maternal diet. Ordered logistic regression modeling was used to determine whether associations described in bivariate analysis persisted after adjusting for maternal age and education as well as household assets. These covariates were chosen based on conceptual and statistical considerations (including the need to avoid collinearity and overfitting models). Ordinary least squares modeling was conducted for outcomes that were continuous (mother's dietary diversity and frequency of eating in the previous 24 hours).

\section{Results}

According to results presented in Table 1, most respondents were Christian, had a primary school education or higher, were literate, and lived a long distance from markets (27.8 minutes on average to reach the closest market) and health facilities (on average, a 33.9-minute trip). About a third of the sample (34.1 percent) had received any antenatal care during their most recent pregnancy or had been advised from any source about nutrition when most recently pregnant (37.0 percent). More than half (56.9 percent) received no professional counselling during their most recent pregnancy and 68.0 percent had never had a CHW speak to them about their children's health. Only one in ten (9.4 percent) of mothers had participated in a women's group of any kind. Per self-reports, only 8.0 percent of mothers ate more 
than usual during their most recent pregnancy and 7.1 percent ate more types of foods. About a quarter of women (24.1 percent) consumed flesh foods in the previous 24 hours while 1.2 percent had eaten eggs and 4.8 percent consumed vitamin A-rich foods (Table 1). A large percentage of mothers had not consumed meat (61.2 percent), fish (41.0 percent), eggs ( 89.5 percent), nor fruit (69.4 percent) in the previous week (results not shown in table form). 
Table 1

Descriptive statistics for background variables, behavioral determinants, and maternal diet

\begin{tabular}{|c|c|c|}
\hline & $\mathbf{n}$ & $\begin{array}{l}\text { Mean } \\
\text { or } \%\end{array}$ \\
\hline \multicolumn{3}{|l|}{ Mother } \\
\hline Ethnicity (ref: Waskom) & 5000 & 42.7 \\
\hline Wahaya & & 12.7 \\
\hline Other & & 40.0 \\
\hline Religion (ref: Christian Protestant) & 5000 & 8.9 \\
\hline Christian, Catholic & & 43.5 \\
\hline Other Christian & & 41.7 \\
\hline Muslim & & 5.9 \\
\hline Years of schooling, mother (ref: no education) & 5000 & 19.1 \\
\hline Primary incomplete & & 11.9 \\
\hline Primary complete & & 56.2 \\
\hline Secondary or more & & 12.9 \\
\hline Maternal literacy (ref: no) & 5000 & 25.9 \\
\hline Yes & & 74.1 \\
\hline Maternal age (ref: 15-19 y) & 4645 & 10.8 \\
\hline $20-29 y$ & & 54.8 \\
\hline $30-39$ y & & 27.7 \\
\hline $40-49$ y & & 5.8 \\
\hline $50+y$ & & 0.9 \\
\hline Mother personally owns a mobile phone & 4997 & 40.8 \\
\hline \multicolumn{3}{|l|}{ Household } \\
\hline Household construction (index: $3-9$; mean) & 5000 & 5.3 \\
\hline Household asset ownership (index $0-13$; mean) & 5000 & 4.2 \\
\hline Household has a radio & 5000 & 47.5 \\
\hline Household has a TV & 5000 & 11.7 \\
\hline Number of other children in the family (mean) & 5000 & 1.6 \\
\hline
\end{tabular}


n

Mean

or \%

\section{Community}

Access to market (travel time, mean, in minutes)

$5000 \quad 27.8$

Access to health facility (travel time, mean, in minutes)

$5000 \quad 33.9$

\section{Access to health services}

Mother received any antenatal care in most recent pregnancy

$4642 \quad 34.1$

Mother received advice on maternal nutrition from any source before her

$4966 \quad 16.9$

pregnancy

Mother received advice on maternal nutrition from any source during her pregnancy

$4958 \quad 37.0$

Mother received advice on maternal nutrition from any source after she gave birth

to youngest child

Times mother was exposed to nutrition counselling before and during pregnancy and after giving birth to youngest child

0

$4951 \quad 56.9$

1

16.6

2

16.1

3

10.4

The last time a community health worker spoke with the mother about the child's health generally

Before or during most recent pregnancy

$5000 \quad 6.0$

In the first few weeks and months after delivery

$5000 \quad 12.6$

Some other time

$5000 \quad 13.4$

No community health worker gave advice

$5000 \quad 68.0$

Mother participates in any women's groups

$4995 \quad 9.4$

\section{Access to land and fresh foods}

Size of plot household cultivates for home garden and/or other agricultural land

$5000 \quad 1.2$ (mean, in acres)

Mother buys fresh foods daily or a few times a week $4986 \quad 67.3$ 


\begin{tabular}{|c|c|c|}
\hline & $\mathrm{n}$ & $\begin{array}{l}\text { Mean } \\
\text { or } \%\end{array}$ \\
\hline Quantity of food mother ate during her most recent pregnancy & 4645 & \\
\hline Less than usual & & 37.2 \\
\hline Same as usual & & 54.8 \\
\hline More than usual & & 8.0 \\
\hline Mother's frequency of eating in previous 24 hours & 4972 & \\
\hline $0-1$ times & & 1.7 \\
\hline 2 times & & 21.3 \\
\hline 3 times & & 35.3 \\
\hline 4 times & & 22.2 \\
\hline 5 or more times & & 19.6 \\
\hline Mean & & $\begin{array}{l}3.4 \\
(95 \% \mathrm{Cl} \\
3.4 \\
3.5)\end{array}$ \\
\hline During her most recent pregnancy, mother ate: & 4648 & \\
\hline Fewer types of foods & & 31.9 \\
\hline Same types of foods & & 61.0 \\
\hline More types of foods & & 7.1 \\
\hline \multicolumn{3}{|l|}{ Type of food mother consumed in previous 24 hours } \\
\hline Cereal & 5000 & 95.0 \\
\hline Legumes and nuts & 5000 & 36.0 \\
\hline Dairy & 5000 & 2.5 \\
\hline Flesh foods & 5000 & 24.1 \\
\hline Eggs & 5000 & 1.2 \\
\hline Vitamin A-rich fruits & 5000 & 4.8 \\
\hline Other fruits & 5000 & 5.1 \\
\hline Mother's dietary diversity in previous 24 hours (7-item scale) & 5000 & \\
\hline 0 types of food & & 3.0 \\
\hline
\end{tabular}




\begin{tabular}{|c|c|c|}
\hline & $\mathbf{n}$ & $\begin{array}{l}\text { Mean } \\
\text { or } \%\end{array}$ \\
\hline 1 type of food & & 40.2 \\
\hline 2 types of food & & 44.7 \\
\hline 3 types of food & & 10.2 \\
\hline 4 types of food & & 1.6 \\
\hline 5 types of food & & 0.3 \\
\hline 6 types of food & & 0.1 \\
\hline 7 types of food & & 0.1 \\
\hline Mean & & $\begin{array}{l}1.7 \\
(95 \% \mathrm{Cl} \\
1.7 \\
1.7)\end{array}$ \\
\hline
\end{tabular}

Factors associated with eating more than usual during pregnancy included receiving any antenatal care, receiving advice about maternal nutrition during and after pregnancy (but not before), and speaking with a CHW about child health (Table 2). However, in many instances, these differences were small. For example, 9.2 percent of women who received any ANC during their most recent pregnancy and 7.3 percent of women who did not, ate more than usual during pregnancy. Receiving any ANC; being counselled about nutrition before, during and after pregnancy; being advised at least once about nutrition; and speaking with a $\mathrm{CHW}$ about child health generally were associated with eating more types of foods during pregnancy. All program exposure variables were significantly associated with mothers' frequency of eating in the previous 24 hours ( $p<0.001$ for all comparisons). Mothers' dietary diversity over the same time period was associated with receiving any ANC, receiving advice about maternal nutrition during and after pregnancy (but not before), and speaking with a CHW about their child's health. 
Table 2

Associations between health services and food consumption during pregnancy and in the previous 24 hours

\begin{tabular}{|c|c|c|c|c|c|c|c|c|}
\hline \multirow{3}{*}{$\begin{array}{l}\text { Recall period: } \\
\text { Variable }\end{array}$} & \multicolumn{4}{|c|}{ Most recent pregnancy } & \multicolumn{4}{|c|}{ Last 24 hours } \\
\hline & \multicolumn{2}{|c|}{$\begin{array}{l}\text { Mother ate } \\
\text { more than } \\
\text { usual during } \\
\text { pregnancy }\end{array}$} & \multicolumn{2}{|c|}{$\begin{array}{l}\text { Mother ate } \\
\text { more types } \\
\text { of foods }\end{array}$} & \multicolumn{2}{|c|}{$\begin{array}{l}\text { Mother's } \\
\text { frequency of } \\
\text { eating }\end{array}$} & \multicolumn{2}{|c|}{$\begin{array}{l}\text { Dietary } \\
\text { diversity }\end{array}$} \\
\hline & $\%$ & $\mathrm{P}$ & $\%$ & $\mathrm{P}$ & Mean & $P$ & Mean & $P$ \\
\hline \multicolumn{9}{|c|}{$\begin{array}{l}\text { Mother received any ANC in } \\
\text { the most recent pregnancy }\end{array}$} \\
\hline Yes & 9.2 & 0.019 & 9.9 & $<.001$ & 3.7 & $<.001$ & 1.7 & 0.004 \\
\hline No & 7.3 & & 5.7 & & 3.3 & & 1.7 & \\
\hline \multicolumn{9}{|c|}{$\begin{array}{l}\text { Mother received advice on } \\
\text { maternal nutrition from any } \\
\text { source before her pregnancy }\end{array}$} \\
\hline Yes & 8.7 & 0.424 & 11.2 & $<.001$ & 3.8 & $\begin{array}{l}< \\
0.001\end{array}$ & 1.7 & 0.226 \\
\hline No & 7.8 & & 6.3 & & 3.4 & & 1.7 & \\
\hline \multicolumn{9}{|c|}{$\begin{array}{l}\text { Mother received advice on } \\
\text { maternal nutrition from any } \\
\text { source during her pregnancy }\end{array}$} \\
\hline Yes & 9.7 & 0.001 & 9.6 & $<001$ & 3.6 & $<001$ & 1.8 & $\begin{array}{l}<.001 \\
0.00\end{array}$ \\
\hline No & 6.9 & & 5.7 & & 3.4 & & 1.6 & \\
\hline \multicolumn{9}{|c|}{$\begin{array}{l}\text { Mother received advice on } \\
\text { maternal nutrition from any } \\
\text { source after she gave birth to } \\
\text { youngest child }\end{array}$} \\
\hline Yes & 9.4 & 0.038 & 9.3 & 0.001 & 3.6 & $\begin{array}{l}< \\
0.001\end{array}$ & 1.8 & $\begin{array}{l}< \\
0.001\end{array}$ \\
\hline No & 7.5 & & 6.4 & & 3.4 & & 1.6 & \\
\hline \multicolumn{9}{|c|}{$\begin{array}{l}\text { Mother was advised at least } \\
\text { once about nutrition before } \\
\text { and during pregnancy and } \\
\text { after giving birth to youngest } \\
\text { child }\end{array}$} \\
\hline Yes & 9.5 & 0.001 & 9.1 & $<.001$ & 3.5 & $\begin{array}{l}<.001 \\
0\end{array}$ & 1.8 & $\begin{array}{l}< \\
0.001\end{array}$ \\
\hline
\end{tabular}




\begin{tabular}{|lllllllll|}
\hline Recall period: & \multicolumn{7}{l}{ Most recent pregnancy } & \multicolumn{4}{l|}{ Last 24 hours } \\
\hline No & 6.8 & & 5.6 & 3.3 & 1.6 & \\
$\begin{array}{l}\text { CHW spoke with mother } \\
\text { about child health generally }\end{array}$ & & & & & & & & \\
\hline Yes, advice at any time & 9.7 & 0.004 & 8.3 & 0.016 & 3.6 & $<$ & 1.8 & 0.001 \\
\hline No & 7.2 & & 6.4 & & 3.3 & & 1.6 & \\
\hline $\begin{array}{l}\text { Mother participates in any } \\
\text { women's groups }\end{array}$ & & & & & & & & \\
\hline Yes & 7.6 & 0.789 & 7.6 & 0.674 & 3.6 & $<$ & 1.7 & 0.127 \\
\hline No & 8.0 & & 7.1 & & 3.4 & & 1.7 & \\
\hline
\end{tabular}

Results from ordered logistic regression models that adjusted for mother's age, education and household assets (Table 3 ) suggest that only one variable (receiving advice on nutrition during 
Table 3

Ordered logistic regression: Association between development assistance, health services, and mother's dietary practices

\section{Mother ate more food during her most recent pregnancy}

Mother ate more types of foods during her most recent pregnancy

AOR $\quad 95 \% \mathrm{Cl} \quad \mathrm{P} \quad$ AOR $\quad 95 \% \mathrm{Cl} \quad \mathrm{P}$

\section{Access to health services}

\begin{tabular}{lccccccc}
$\begin{array}{l}\text { Mother received any antenatal care in most } \\
\text { recent pregnancy }\end{array}$ & 1.2 & $\begin{array}{l}1.0, \\
1.5\end{array}$ & 0.111 & 1.7 & $1.3,2.1$ & $<0.001$ \\
$\begin{array}{l}\text { Mother received advice on maternal } \\
\text { nutrition from any source before her } \\
\text { pregnancy }\end{array}$ & 1.1 & $\begin{array}{l}0.8, \\
1.4\end{array}$ & 0.730 & 1.8 & $1.4,2.3$ & $<0.001$ \\
$\begin{array}{l}\text { Mother received advice on maternal } \\
\text { nutrition from any source during her } \\
\text { pregnancy }\end{array}$ & 1.3 & $\begin{array}{l}1.1, \\
1.7\end{array}$ & & 0.010 & 1.7 & $1.3,2.1$ & $<0.001$ \\
$\begin{array}{l}\text { Mother received advice on maternal } \\
\text { nutrition from any source after she gave }\end{array}$ & 1.2 & $\begin{array}{l}1.0, \\
1.5\end{array}$ & 0.102 & 1.4 & $1.1,1.8$ & 0.003 \\
\hline
\end{tabular}
birth to youngest child

The last time a community health worker spoke with the mother about the child's health generally

No community health worker gave advice (ref)

\begin{tabular}{lcccccc} 
Before most recent pregnancy & 2.2 & $\begin{array}{l}0.9, \\
5.4\end{array}$ & 0.078 & 0.7 & $0.2,2.9$ & 0.631 \\
During most recent pregnancy & 1.1 & $\begin{array}{l}0.7, \\
1.9\end{array}$ & 0.585 & 1.1 & $0.6,1.8$ & 0.778 \\
& 1.2 & $\begin{array}{l}0.9, \\
1.7\end{array}$ & 0.260 & 1.5 & $1.1,2.0$ & 0.015 \\
\hline $\begin{array}{l}\text { In the first few weeks and months after } \\
\text { delivery }\end{array}$ & 1.3 & $\begin{array}{l}1.0, \\
1.8\end{array}$ & 0.066 & 2.0 & $0.9,1.7$ & 0.293 \\
Some other time & & & & & \\
\hline Mother participates in any women's groups & 1.0 & $\begin{array}{l}0.7, \\
1.4\end{array}$ & 0.904 & 1.0 & $0.7,1.5$ & 0.810 \\
\hline
\end{tabular}

Note: Adjusted for mother's age and education and household assets.

pregnancy) was associated with the mother eating more food during her most recent pregnancy. Women who received advice were 1.3 times $(95 \% \mathrm{Cl}: 1.1,1.7)$ more likely than mothers who did not receive advice to eat more during pregnancy. In contrast, women who received ANC and advice on nutrition before, during, and after pregnancy and birth were all significantly more likely than women who did not to eat 
more types of foods. Hearing from a CHW about their child's health and participating in support groups were largely not associated with eating more types of foods.

According to results from ordinary least squares models (Table 4), women who received advice about maternal nutrition during and after pregnancy, who had heard CHWs' advice about child health generally, and who had participated in any women's group were significantly $(p<0.05)$ more likely than women who had not to eat more frequently in the previous 24 hours. Additionally, mothers who received ANC care; those who received advice about maternal nutrition from any source before, during, and after pregnancy; and mothers hearing from $\mathrm{CHWs}$ during and after delivery about the child's health were generally more likely than those who did not receive care nor counselling to consume a more diverse diet in the previous 24 hours, after adjusting for mother's age and education and household assets $(p<0.01$ for all comparisons found to be significant). 
Table 4

Ordinary least squares: Associations between access to development assistance, health services, and mother's dietary diversity

\section{Mother's frequency of eating in Mother's dietary diversity in previous 24 hours previous 24 hours, 7-item scale}

Coefficient $95 \% \mathrm{Cl} \quad \mathrm{p} \quad$ Coefficient $95 \% \mathrm{Cl} \quad \mathrm{p}$

\section{Access to health services}

\begin{tabular}{|c|c|c|c|c|c|c|}
\hline $\begin{array}{l}\text { Mother received any antenatal } \\
\text { care in most recent pregnancy }\end{array}$ & 0.2350 & $\begin{array}{l}0.1697 \\
0.3003\end{array}$ & $<001$ & 0.0179 & $\begin{array}{l}-0.0321 \\
-0.0679\end{array}$ & 0.484 \\
\hline $\begin{array}{l}\text { Mother received advice on } \\
\text { maternal nutrition from any } \\
\text { source before her pregnancy }\end{array}$ & 0.3426 & $\begin{array}{l}0.2633 \\
0.4220\end{array}$ & $\begin{array}{l}< \\
0.001\end{array}$ & -0.0258 & $\begin{array}{l}-0.0866 \\
0.0351\end{array}$ & 0.406 \\
\hline $\begin{array}{l}\text { Mother received advice on } \\
\text { maternal nutrition from any } \\
\text { source during her pregnancy }\end{array}$ & 0.0959 & $\begin{array}{l}0.0330 \\
0.1588\end{array}$ & 0.003 & 0.0722 & $\begin{array}{l}0.0243 \\
0.1201\end{array}$ & 0.003 \\
\hline $\begin{array}{l}\text { Mother received advice on } \\
\text { maternal nutrition from any } \\
\text { source after she gave birth to } \\
\text { youngest child }\end{array}$ & 0.1888 & $\begin{array}{l}0.1205, \\
0.2571\end{array}$ & $\begin{array}{l}< \\
0.001\end{array}$ & 0.1094 & $\begin{array}{l}0.0573, \\
0.1615\end{array}$ & $\hat{0}_{0.001}$ \\
\hline
\end{tabular}

The last time a community health worker spoke with the mother about the child's health generally

No community health worker gave advice (ref)

\begin{tabular}{|c|c|c|c|c|c|c|}
\hline Before most recent pregnancy & 0.2232 & $\begin{array}{l}-0.0837 \\
0.5301\end{array}$ & 0.154 & -0.0238 & $\begin{array}{l}-0.2563 \\
0.2087\end{array}$ & 0.841 \\
\hline During most recent pregnancy & 0.4812 & $\begin{array}{l}0.3450 \\
0.6173\end{array}$ & $\begin{array}{l}< \\
0.001\end{array}$ & 0.3133 & $\begin{array}{l}0.2090 \\
0.4175\end{array}$ & $\begin{array}{l}< \\
0.001\end{array}$ \\
\hline $\begin{array}{l}\text { In the first few weeks and } \\
\text { months after delivery }\end{array}$ & 0.2536 & $\begin{array}{l}0.1627 \\
0.3445\end{array}$ & $\begin{array}{l}< \\
0.001\end{array}$ & 0.0421 & $\begin{array}{l}-0.0273, \\
0.1112\end{array}$ & 0.235 \\
\hline Some other time & 0.0534 & $\begin{array}{l}-0.0365 \\
0.1432\end{array}$ & 0.244 & 0.0856 & $\begin{array}{l}0.0169 \\
0.1543\end{array}$ & 0.015 \\
\hline $\begin{array}{l}\text { Mother participates in any } \\
\text { women's groups }\end{array}$ & 0.1594 & $\begin{array}{l}0.0566 \\
0.2623\end{array}$ & 0.002 & 0.0256 & $\begin{array}{l}-0.0528 \\
0.1041\end{array}$ & 0.522 \\
\hline
\end{tabular}

Note: Adjusted for mother's age and education and household assets.

\section{Discussion}

This paper examined potential associations between existing access to health services and other sources of advice about nutrition and women's dietary practices during pregnancy and post-partum. We found 
that only 34 percent of women received any ANC, a sharp contrast to national figures which indicate that 98 percent of all pregnant women receive at least some antenatal care [7]. Consistent with study hypotheses, we found that mothers who had made at least one ANC visit, had heard advice about their own nutrition and the health of their child, and to a lesser extent, had benefited from visits by CHWs, were more likely to consume a diverse diet. These findings are largely consistent with the existing literature. Gludeirard and Olude [21] note that nutrition education and counselling have mostly been associated with improved maternal dietary practices. In India, Ghosh-Jerath and colleagues [22] found that ANC visits were associated with protein uptake. In Nepal, Sunuwar and collaborators [23] documented significantly higher intake of red meat, fish and liver, vitamin C-rich fruits, dairy products, eggs, and green leafy vegetables among women making ANC visits. In Egypt and in Senegal, exposure to positive deviance programs was associated with consuming more meat and vegetables [24] and iron supplements [25]. In a large study from Bangladesh, relative to a standard maternal, neonatal, and child health package, women who received intensive nutrition counselling via salaried health workers and incentivized community health volunteers, monthly home visits, one-on-one ANC sessions with individually-tailored diet plans, and nutrition promotion activities among family members were more likely to consume a greater number of food groups, specific foods, and iron and calcium supplements [26]. In contrast, some studies, including one from Nepal [27], report that women participating in support groups did not have significantly more diverse diets nor protein and energy adequacy than non-participants.

We also found that mothers who received any ANC during pregnancy ate more frequently, compared to women who did not receive such services. There is considerably less literature on nutrition promotion and feeding frequency but Demilew and colleagues [28] and Diddana [29] report from their observational study in Ethiopia that knowledge about diet during pregnancy was associated with consuming foods more frequently.

Our findings indicate that mothers who received advice on maternal nutrition from any source during pregnancy self-reported eating more food compared to mothers who did not receive such advice, a finding noted by Ahrari and colleagues [24] in Egypt and Nguyen and colleagues [26] in Bangladesh. It may be that it is easier for women to increase the diversity of the foods they eat relative to increasing the amount of foods they consume and how frequently they consume food, though little has been written about this topic.

In addition to program exposure, other factors are known to influence nutrition behaviors. These include women's knowledge of nutrition, perceived severity of malnutrition, poor perceived benefits of adopting healthy nutrition practices, and low self-efficacy [28-30].

Findings reported here demonstrate at least modest associations between access to health facility and community-based services and a range of nutrition-related behaviors. However, only a third of our sample received any ANC during their most recent pregnancy and a similarly low percent received nutrition advice from any source. More than half of women received no professional counselling during their most recent pregnancy and two-thirds had never had a CHW speak to them about their children's health. Just one in 
ten mothers had participated in a women's group of any kind. Other studies in Tanzania also report low exposure to facility-based counselling and frontline health worker activities [7,31]. While our results regarding the potential impact of $\mathrm{ANC}$ and $\mathrm{CHW}$ counselling are encouraging, population-level changes in nutrition behaviors are unlikely to occur at the scale reported in Bangladesh and elsewhere [27], barring major efforts to scale up current interventions. Nguyen and colleagues note that in Bangladesh, among seven program elements, differences in intervention coverage were one of two factors that best explained the lack of program impact [26].

Achieving scale is only one potential challenge to improving nutrition behaviors. Others include health worker shortages such as a lack of dieticians [32], low salaries [33], health workers' shortage of time [28], adequate information and training to counsel women [13,32-34], and uncertainty about how to translate general nutrition requirements to individual needs [13].

We used project baseline data from a large survey to explore the relationship between exposure to existing government programs and dietary practices among women in a specific geographic region of Tanzania. Our findings provide useful information to policy makers and program planners who are tasked with improving women's nutrition. However, our study has limitations. These include lack of more detailed measures of the quality, timing, and nature of programs and source of nutrition information (for example, clinicians versus $\mathrm{CHWs}$ versus family members or friends); Additionally, data are cross-sectional and only include information on exposure to existing government services, thus limiting our ability to document changes in program exposure and nutritional practices over time. Additional analyses based on the ASTUTE project's midline and endline will shed light on apparent anomalies in our findings, for example, that counseling after pregnancy was associated with eating more foods and more types of foods during pregnancy.

A number of factors influence women's diets, including production of nutritious, diverse foods; women's position within the household, including control over resources and decision-making power; how foods that the household uses are produced; what crops are designated for home consumption; cultural beliefs about what foods women should eat during pregnancy and lactation; and the emotional and instrumental support other family members offer to promote dietary behaviors known to improve women's nutrition [8, 35]. Programs designed to improve women's dietary behaviors can benefit from efforts to bolster both the number and preparedness of health workers (including training to standardize innovative counselling and community-based behavior change strategies), a re-structuring of salaries and incentives for health workers, greater time allocation for nutrition education and counselling, and more supportive supervision. Standardization of roles and responsibilities, job aids, and frequent monitoring of nutrition education and counselling are critical to implementing high-quality interventions.

Future research would benefit from elucidating how the timing, content, and source of counselling and community mobilization impact upon women's dietary behaviors [16, 36]. Intervention research that more fully characterizes programs [37] and elucidates how and why interventions achieve impact will benefit 
policy and program design and implementation. Rigorous program fidelity assessments can pinpoint which of various program elements might explain the impact of a given intervention.

\section{Conclusions}

Consistent with much of the existing literature, our research reinforces the importance of receiving advice about nutrition and health from health facility workers and frontline health workers/volunteers before and during pregnancy as well as post-partum. Given the impact of nutrition education and counselling on women's diets, it is essential that future attempts to improve women's dietary behaviors consider the complex environment within which women operate. Improving mothers' diets should include training and supportive supervisory systems, the introduction of proven counselling and behavior change strategies, community social mobilization and greater political will to extend health facility and community-based outreach.

\section{Abbreviations}

ANC Antenatal care

ASTUTE Addressing stunting early in Tanzania

CHW Community health worker

DFID Department for International Development

MDD-W Minimum Dietary Diversity for Women

LMICs Low- and middle-income countries

TDHS Tanzanian Demographic and Health Survey

\section{Declarations}

\section{Ethics approval and consent to participate:}

The National Institute for Medical Research in Tanzania and relevant local government authorities authorized the research (NIMR/HQ/R.8a/Vol.IX/2344).

We obtained informed consent from all study participants-written if the respondent was literate and by thumb print if not. The ethics committee approved the procedure for thumbprint consent from illiterate participants. All methods were performed in accordance with the relevant guidelines and regulations.

\section{Consent for publication:}




\section{Availability of data and materials:}

The datasets generated and analysed during the current study are not publicly available due to concerns about the confidentiality of individual respondents but are available from the corresponding author on reasonable request.

\section{Competing interests:}

The authors declare that they have no competing interests.

\section{Funding:}

The ASTUTE program (contract number PO 6803) was funded by the Department for International Development (DfID) of the United Kingdom. DfID had no role in the design of the study, data collection, data analysis, and interpretation of data nor in writing the manuscript. The authors' views expressed in this publication do not necessarily reflect the views of IMA World Health, Brigham Young University, nor DfID.

KAD, BTM, BTC, and GIM conceived and designed the work. KAD and BTM acquired the data. KAD conducted data analysis. All authors interpreted the data. All authors drafted the work or substantively revised it. All authors approved the submitted version. All authors have agreed both to be personally accountable for their own contributions and to ensure that questions related to the accuracy or integrity of any part of the work are appropriately investigated, resolved, and the resolution documented in the literature.

\section{Acknowledgements:}

Not applicable.

\section{Authors' information (optional):}

Not applicable.

\section{References}

1. Stevens GA, Finucane MM, De-Regil LM, Paciorek CJ, Flaxman SR, Branca F, et al. Global, regional, and national trends in haemoglobin concentration and prevalence of total and severe anaemia in 
children and pregnant and non-pregnant women for 1995-2011: a systematic analysis of population-representative data. Lancet Glob Health. 2013; 1(1):e16-25.

2. Development Initiatives. Global nutrition report 2017: nourishing the SDGs. Bristol, UK: Development Initiatives; 2017.

3. World Health Organization. Global Health Observatory data repository: prevalence of anaemia in women, estimates by country. In: World Health Organization; [Internet]. 2017.

4. Black RE, Victora CG, Walker SP, Bhutta ZA, Christian P, de Onis M, et al. Maternal and child undernutrition and overweight in low-income and middle-income countries. Lancet. 2013;382:42751.

5. World Health Organisation (WHO)/Centers for Disease Control and Prevention (CDC). Worldwide prevalence of anemia 1993-2005: WHO global database on anaemia. In de Benoist B, McLean, E, Egli I, Cogswell M, editors. Geneva: WHO Press; 2008.

6. Black RE, Allen LH, Bhutta ZA, Caulfield L, de Onis M, Ezzati M., et al. Maternal and child undernutrition: global and regional exposures and health consequences. 2008;371(9608):243-60.

7. Ministry of Health, Community Development, Gender, Elderly and Children (MoHCDGEC) [Tanzania Mainland], Ministry of Health (MoH) [Zanzibar], National Bureau of Statistics (NBS), Office of the Chief Government Statistician (OCGS), and ICF. Tanzania Demographic and Health Survey and Malaria Indicator Survey (TDHS-MIS) 2015-16. Dar es Salaam, Tanzania and Rockville, Maryland, USA: MoHCDGEC, MoH, NBS, OCGS, and ICF; 2016.

8. Ochieng J, Afari-Sefa V, Lukumay PJ, Dubois T. Determinants of dietary diversity and the potential role of men in improving household nutrition in Tanzania. PLoS One. 2017;12:1-18.

9. Girard AW, Akogun CD, Mason JB, Mcfarland D. Public health interventions, barriers, and opportunities for improving maternal nutrition in Northeast Nigeria. Food and Nutrition Bulletin. 2012;33(2, supplement):S51-70.

10. Garg A, Kashyap S. Effect of counseling on nutritional status during pregnancy. Indian J 2006;73(8):687-92.

11. Ota E, Hori H, Mori R, Tobe-Gai R, Farrar D. Antenatal dietary education and supplementation to increase energy and protein intake. Cochrane Systematic Review - Intervention. 2015; Art. No.:CD000032.

12. Shreekumar Girard AW, Olude O. Nutrition education and counselling provided during pregnancy: effects on maternal, neonatal and child health outcomes. Paediatr Perinat Epidemiol. 2012;26:191204.

13. Nnam N. Improving maternal nutrition for better pregnancy outcomes. Proc Nutr Soc. 2015;74(4):454-9.

14. Ramakrishnan U, Grant F, Goldenberg T, Zongrone A, Martorell R. Effect of women's nutrition before and during early pregnancy on maternal and infant outcomes: a systematic review. Paediatr Perinat Epidemiolog. 2012;26:285-301. 
15. Mason, J. B., Shrimpton, R., Saldanha, L. S., Ramakrishnan, U., Victora, C. G., Girard, A. W., et al. The first 500 days of life: policies to support maternal nutrition. Glob Health Action. 2014;7:23623.

16. World Health Organisation (WHO). WHO recommendations on antenatal care for a positive pregnancy experience. Geneva: WHO Press; 2016.

17. Kavle, JA, Landry M. Addressing barriers to maternal nutrition in low- and middle- income countries: a review of the evidence and programme implications. Matern Child Nutr. 2017; 14(1):e12508.

18. Ministry of Health, Community Development, Gender, Elderly and Children (MoHCDGEC). The National Road Map Strategic Plan to Accelerate Reduction of Maternal, Newborn and Child Deaths in Tanzania. Dar es Salaam, Tanzania: MoHDGEC; 2015.

19. Mella PP. Major factors that impact on women's health in Tanzania: the way forward. Health Care Women Int. 2003:24:712-22.

20. Food and Agriculture Organization and FHI 360. Minimum dietary diversity for women: a guide for measurement. Rome: FAO; 2016.

21. Girard AW, Olude O. Nutrition education and counselling provided during pregnancy: effects on maternal, neonatal and child health outcomes. Paediatr Perinat Epidemiol. 2012;26:191-204.

22. Ghosh-Jerath S, Devasenapathy N, Singh A, Shankar A, Zodpey S. Antenatal care (ANC) utilization, dietary practices and nutritional outcomes in pregnant and recently delivered women in urban slums of Delhi, India: an exploratory cross-sectional study. Reprod Health. 2015;12:20.

23. Sunuwar DR, Sangroula RK, Shakya NS, Yadav R, Chaudhary NK, Pradhan PMSP. Effect of nutrition education on hemoglobin level in pregnant women: a quasiexperimental study. PLoS One. 2019;14(3):e0213982.

24. Ahrari M, Houser RF, Yassin S, Mogheez M, Hussaini Y. A positive deviance-based antenatal nutrition project improves birth-weight in upper Egypt. J Health Popul Nutr.2006;24:498-507.

25. Ndiaye M, Siekmans K, Haddad S, Receveur O. Impact of a positive deviance approach to improve the effectiveness of an iron-supplementation program to control nutritional anemia among rural Senegalese pregnant women. Food Nutr Bull.2009;30:128-36.

26. Nguyen PH, Sanghvi T, Kim SS, Tran LM, Afsana K, Mahmud Z, et al. Factors influencing maternal nutrition practices in a large scale maternal, newborn and child health program in Bangladesh. PLoS One. 2017;12(7):e0179873.

27. Harris-Fry HA, Paudel P, Harrisson T, Shrestha N, Jha S, Beard J, et al. Participatory women's groups with cash transfers can increase dietary diversity and micronutrient adequacy during pregnancy, whereas women's groups with food transfers can increase equity in intrahousehold energy allocation. J Nutr. 2018;148(9);1472-83.

28. Demilew YM, Alene GD, Belachew T. Dietary practices and associated factors among pregnant women in West Gojjam Zone, Northwest Ethiopia. BMC Pregnancy Childb. 2020;20:18. .

29. Diddana TZ. Factors associated with dietary practice and nutritional status of pregnant women in Dessie town, northeastern Ethiopia: a community-based cross-sectional study. BMC Pregnancy Childb. 2019;19,517. 
30. Nana, A, Zema T. Dietary practices and associated factors during pregnancy in northwestern Ethiopia. BMC Pregnancy Childb. 2018;18:183.

31. Geldsetzer P, Mboggo E, Larson E, Lema IA, Magesa L, Machumi L, et al. Community health workers to improve uptake of maternal healthcare services: a cluster-randomized pragmatic trial in Dar es Salaam, Tanzania. PLoS Med. 2019;16(3):e1002768.

32. Murphy AJ, Mosby TT, Rogers PC, Cohen J, Ladas EJ. An international survey of nutritional practices in low- and middle-income countries: a report from the International Society of Pediatric Oncology (SIOP) PODC Nutrition Working Group. 2014;68(12):1341-5. doi: 10.1038/ejcn.2014.122. Epub 2014 Jul 2.

33. Adamski M, Gibson S, Leech M, Truby H. Are doctors nutritionists? What is the role of doctors in providing nutrition advice?Eur J Clin Nutr. 2014;68(12):1341-5.

34. Pelto GH, Santos I, Gonçalves H, Victora C, Martines J, Habicht J-P. Nutrition counseling training changes physician behavior and improves caregiver knowledge acquisition. $J$ Nutr. 2004;134(2):357-62.

35. Malapit H, Quisumbing, A. Gendered pathways to better nutrition. Rural21. 2016;01: 15-17.

36. Nguyen PH, Frongillo EA, Sanghvi T, Kim SS, Alayon S, Tran LM, et al. Importance of coverage and quality for impact of nutrition interventions delivered through an existing health programme in Bangladesh. Matern Child Nutr. 2018;14(4):e12613.

37. Pelto GH, Santos I, Gonçalves H, Victora C, Martines J, Habicht J-P. Nutrition counseling training changes physician behavior and improves caregiver knowledge acquisition. J Nutr. 2004;134(2): 357-62. 